\title{
Minireview
}

-

neas

\section{Fibroblast Growth Factor 23/Klotho Axis in Chronic Kidney Disease}

\author{
Kosaku Nitta ${ }^{a}$ Nobuo Nagano $^{b}$ Ken Tsuchiya ${ }^{a}$ \\ ${ }^{a}$ Kidney Center, Department of Medicine, Tokyo Women's Medical University, Tokyo, and b Kidney Disease and \\ Dialysis Center, Hidaka Hospital, Takasaki, Japan
}

\section{Key Words}

FGF23 · Klotho $\cdot$ CKD-MBD $\cdot$ Phosphate $\cdot$

Vascular calcification

\begin{abstract}
Fibroblast growth factor-23 (FGF23) is a bone-derived hormone that regulates phosphate and 1,25-hydroxyvitamin $D$ $\left[1,25(\mathrm{OH})_{2} \mathrm{D}\right]$ metabolism. FGF23 binds to FGF receptor 1 with its coreceptor Klotho and maintains serum phosphate levels within the normal range by increasing renal phosphate excretion. In addition, FGF23 reduces the synthesis and accelerates the degradation of $1,25(\mathrm{OH})_{2} \mathrm{D}$ to reduce intestinal phosphate absorption. Moreover, FGF23 acts at the parathyroid gland to decrease parathyroid hormone synthesis and secretion. In chronic kidney disease (CKD), serum FGF23 levels rise exponentially as renal function declines long before a significant increase in serum phosphate concentration occurs. Although there is room for argument, FGF23 and Klotho are recently reported contributors to vascular calcification. Finally, prospective observational studies have shown that serum FGF23 concentrations predict mortality not only among dialysis patients but among predialysis CKD patients. In addition to being a coreceptor for FGF23, Klotho circulates as an endocrine substance and exerts a multitude of effects. This review describes recent advances in research on the FGF23-Klotho axis in CKD.
\end{abstract}

(c) 2014 S. Karger AG, Basel

\section{KARGER}

(c) 2014 S. Karger AG, Basel

$1660-2110 / 14 / 1282-0001 \$ 39.50 / 0$

E-Mail karger@karger.com

www.karger.com/nec

\section{Introduction}

Chronic kidney disease (CKD) is the leading risk factor for cardiovascular disease, which is a great threat to health and an economic burden [1]. The growing burden of CKD reflects the impact of the rapidly increasing prevalence of diabetes and hypertension. Moreover, cardiovascular disease is a leading cause of death in CKD [2]. A large cohort study has shown that sustained decrease in estimated glomerular filtration rate (eGFR) is associated with increased rates of coronary heart disease, and death from cardiovascular causes as well as increase in hospitalization [3].

$\mathrm{CKD}$ is accompanied by an inevitable progressive derangement of mineral homeostasis, an imbalance between blood and tissue concentrations of phosphate $(\mathrm{P})$ and calcium $(\mathrm{Ca})$, and changes in circulating levels of phosphotropic hormones. The term CKD-mineral and bone disorder (CKD-MBD) refers to a constellation of features that are exclusively attributable to renal dysfunction, and it is used to describe (a) a broad clinical syndrome that encompasses altered serum levels of $\mathrm{P}, \mathrm{Ca}$, parathyroid hormone (PTH), and vitamin D; (b) impaired bone modeling and remodeling and the associated occurrence of fractures, and (c) extraskeletal calcification in soft tissues and arteries [4].

This review summarizes recent advances in research on the roles of fibroblast growth factor-23 (FGF23) and a-Klotho in regulating the mineral metabolism of CKD patients. 
Fig. 1. Molecular structure of FGF23. The FGF23 protein has the sequence of first 24 amino acid residues that is deduced to be the signal peptide. It has a unique sequence following the FGF-like sequence at the Cterminal. Since the N-terminal amino acid is Ser $^{180}$ located after the consensus sequence (Arg ${ }^{176}$-His ${ }^{177}$ - $\mathrm{Thr}^{178}$ - $\mathrm{Arg}^{179}$ ) recognized by some proprotein convertases, this $10-\mathrm{kDa}$ protein is a likely product of the internal proteolytic cleavage of the mature FGF23 protein.

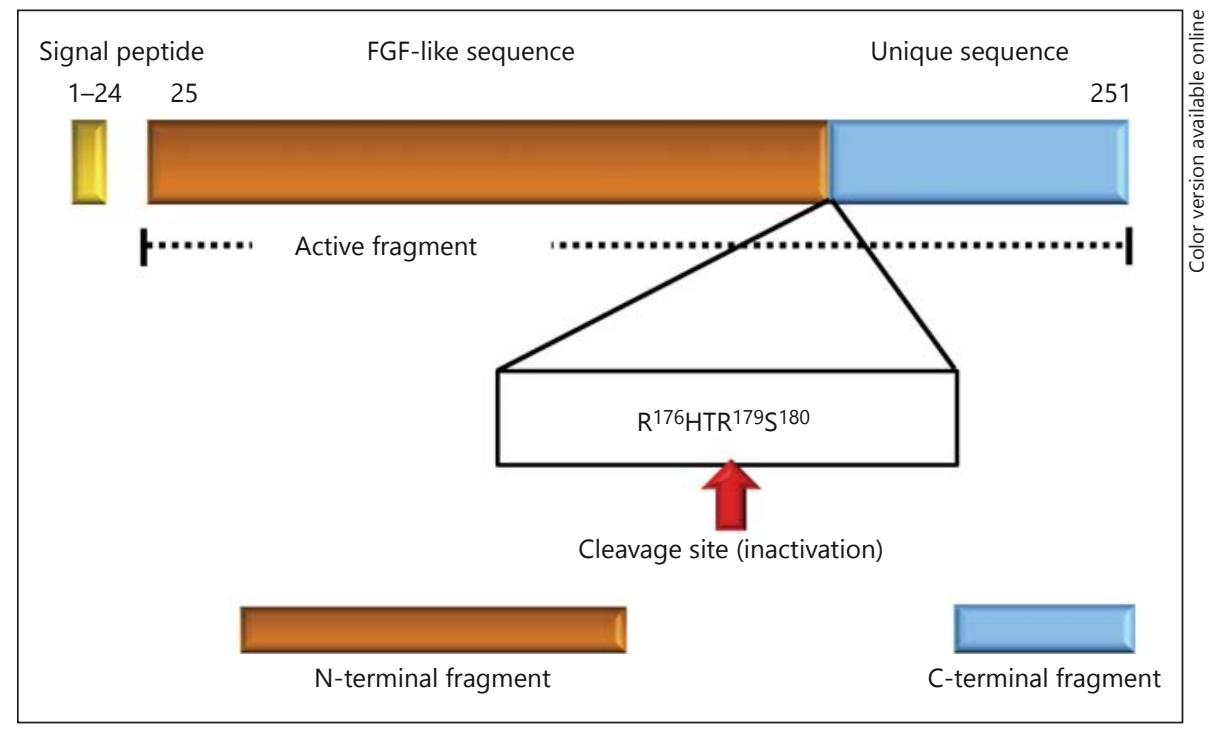

\section{Function of FGF23}

FGF23 is a recently identified hormone that regulates $\mathrm{Ca}$ and $\mathrm{P}$ metabolism [5]. FGF23 is a 251-amino-acid protein (molecular weight: $26 \mathrm{kDa}$ ) that was found to be synthesized and secreted by osteoblasts [6]. However, a recent study has shown that FGF23 is mainly produced by osteocytes [7]. As shown in figure 1, FGF23 is composed of an amino-terminal signal peptide (residues 1-24), an 'FGF-like sequence' (residues 25-179), and a carboxylterminal extended sequence (residues 180-251), which is unique among members of the FGF family [8]. Since FGF23 has low affinity for heparin, it is distributed throughout the body by the blood, and mediates its systemic function [9].

The biological activity and physiological role of FGF23 in $\mathrm{P}$ and vitamin $\mathrm{D}$ metabolism in vivo have recently been clarified. FGF23 directly increases urinary fractional excretion of $\mathrm{P}(\mathrm{FePi})$ by reducing the expression of sodium$\mathrm{P}$ cotransporter type II (NaPi-II) and indirectly reduces $\mathrm{P}$ absorption in the gut by suppressing 25-hydroxyvitamin D-1 $\alpha$-hydroxylase (1 $\alpha$-hydroxylase) activity [10-13]. FGF23 has been found to downregulate the expression of both $\mathrm{NaPi}$-IIa and $\mathrm{NaPi}$-IIc on the apical surface of renal proximal tubular epithelial cells in vivo [14]. Indeed, the injection of recombinant human FGF23 protein decreases serum $\mathrm{P}$ levels by means of its phosphaturic effect that is attributable to reduced renal $\mathrm{P}$ reabsorption in normal mice and parathyroidectomized rats [15]. In addition, FGF23 appears to impair the synthesis and accelerate the degradation of $1,25(\mathrm{OH})_{2} \mathrm{D}$, because expression of renal
mRNA levels of 1a-hydroxylase was reduced and that of 25-hydroxyvitamin D-24 hydroxylase was increased within $1 \mathrm{~h}$ after injection of recombinant human FGF23 protein in normal mice [15]. Therefore, $F g f 23^{-/-}$mice are characterized by increased renal $\mathrm{P}$ reabsorption and an elevated serum $1,25(\mathrm{OH})_{2} \mathrm{D}$ concentration $[16,17]$.

\section{Measurement of Serum FGF23 Levels}

Intact FGF23 in the circulation of healthy individuals has been estimated to have a half-life of $58 \mathrm{~min}$ [18]. Two assays for measurement of human FGF23 are commercially available. One is a sandwich enzyme-linked immunosorbent assay designed to measure full-length FGF23 in which different monoclonal antibodies are used to detect the simultaneous presence of both the N-terminal and C-terminal portions of FGF23 [19]. The other assay is a C-terminal assay that recognizes both full-length and processed (presumably inactive) C-terminal fragments of FGF23 [20]. The intra-assay variability of the C-terminal FGF23 assay is $5 \%$ at $52.7 \mathrm{RU} / \mathrm{ml}$ and $7.2 \%$ at $140.0 \mathrm{RU} /$ $\mathrm{ml}$, and its inter-assay variability is $5 \%$ at $50.9 \mathrm{RU} / \mathrm{ml}$ and $7.3 \%$ at $153.0 \mathrm{RU} / \mathrm{ml}$, and its lower limit of detection is 3.0 $\mathrm{RU} / \mathrm{ml}$. The intra-assay variability of the intact FGF23 assay is $4.4 \%$ at $14.6 \mathrm{pg} / \mathrm{ml}$ and $2.6 \%$ at $148.0 \mathrm{pg} / \mathrm{ml}$, and its inter-assay variability is $6.1 \%$ at $15.6 \mathrm{pg} / \mathrm{ml}$ and $6.5 \%$ at $166.0 \mathrm{pg} / \mathrm{ml}$; its lower limit of detection is $1.0 \mathrm{pg} / \mathrm{ml}$ (according to the manufacturer's specifications). Plasma FGF23 levels have been found to be negatively correlated with eGFR (fig. 2) [21]. Plasma FGF23 concentrations 


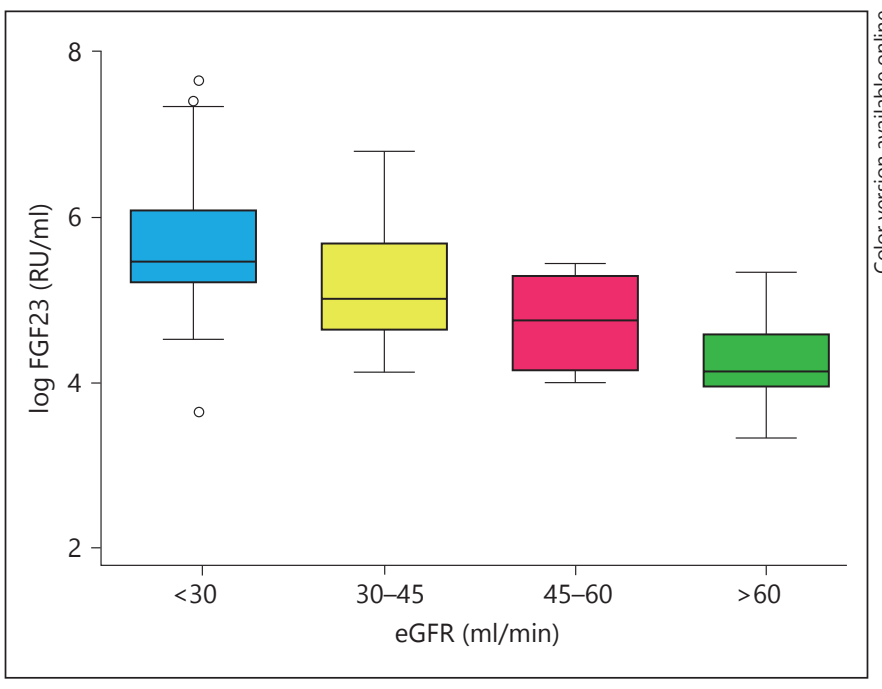

Fig. 2. Plasma FGF23 levels in the four CKD stage groups. Boxes represent the interquartile range with the upper and lower edges representing the 75th and 25th percentiles, respectively. There is a statistically significant linear increase in plasma FGF23 levels across the four CKD groups divided by eGFR [reprinted with permission from 21].

have been found to predict mortality not only among dialysis patients but among predialysis CKD patients as well [22].

\section{Interaction between FGF23 and Klotho}

Klotho is a $130-\mathrm{kDa}$ transmembrane $\beta$-glucuronidase that catalyzes the hydrolysis of steroid $\beta$-glucuronides, and it was discovered by Kuro-o et al. [23] in 1997 (fig. 3). The Klotho gene is expressed in a limited number of organs, mainly in the kidney, and mutations cause multiple aging-related disorders in nearly all organs and tissues [24]. Fgf $23^{-1-}$ mice and Klotho ${ }^{-/-}$mice exhibit almost identical phenotypes that include abnormal mineral metabolism that is characterized by increased blood $\mathrm{P}, \mathrm{Ca}$, and vitamin D levels [25]. Klotho is required for FGF23 to activate FGF receptors (FGFRs) and their downstream signaling molecules (fig. 4), including FGFR substrate-2a and mitogen-activated protein kinases, such as extracellular signal-regulated kinases [26]. Because a Klotho/ FGFR complex binds to FGF23 with higher affinity than either FGFR or Klotho alone, FGF23 exerts its biological effects through activation of FGFRs in a Klotho-dependent manner $[25,26]$.

FGF23 has rather low affinity for its widely distributed receptors, and the presence of circulating Klotho is essen-

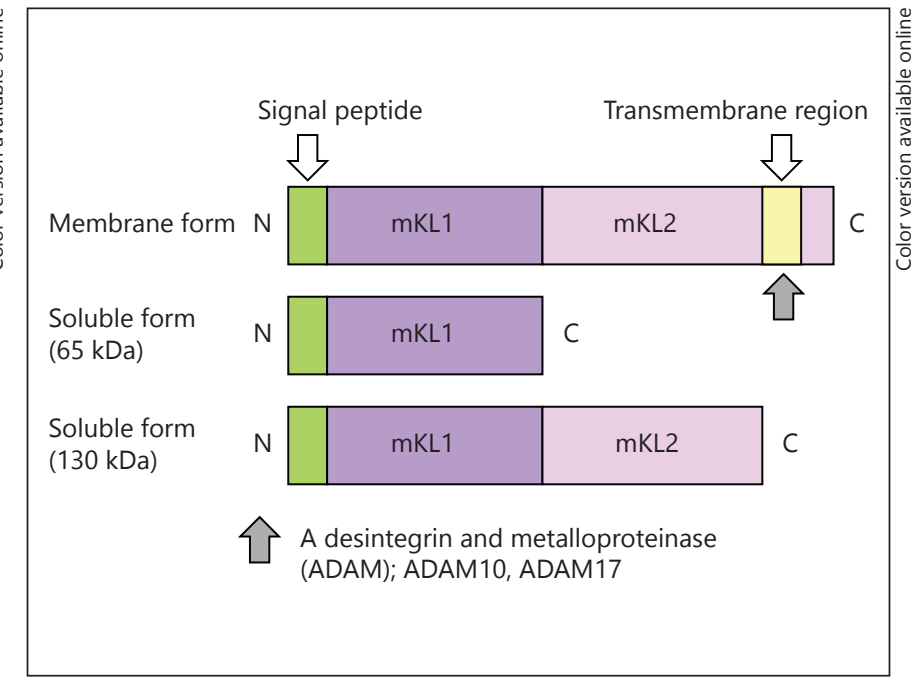

Fig. 3. Klotho family showing the three members identified in the mammalian genome. Homologous motifs termed KL1 domains are conserved. Soluble forms of Klotho can be generated by alternative splicing of its transcript or by proteolytic cleavage of the transmembrane form by $\beta$-secretases into body fluids.

tial to facilitate the binding of FGF23 to FGFRs $[25,26]$. The potential role of soluble Klotho in FGF23 signaling in vivo remains unknown at this time, but appears to be less plausible mechanism for phosphaturia [27], as in vitro assays have shown that the affinity of FGFR1 for the Klotho ectodomain is log-fold lower than their affinity for full-length transmembrane Klotho [25, 26]. Thus, activation of FGFRs requires not only the presence of circulating FGF23 as their ligand, but the presence of Klotho as a specific promoter whose affinity dictates its selectivity for its targets. Klotho is mainly expressed in the kidneys, whereas FGF23 is expressed by bone cells, and this functional bone-kidney axis is of physiological and pathological relevance. Based on available knowledge, the bonekidney axis seems to exert a prevailing regulation of $\mathrm{Ca}$ balance with Klotho and to exert a more specific and direct effect on P homeostasis through FGF23. Although the actions of FGF23 seem to occur in the proximal tubules, Klotho expression is higher in the distal tubules $[23,28]$. Because the proximal tubules also express Klotho, although in smaller quantities [29], FGF23 signal may appear in proximal tubules to regulate their function with a small number of Klotho/FGFR complexes. Another possibility is that FGF23 acts on the distal convoluted tubules, where Klotho is most abundantly expressed [28], and triggers the release of paracrine factors that act on adjacent proximal tubules. 
Fig. 4. Interactions between FGF23, FGF receptor, and Klotho. FGF23 signal transduction is established when FGF receptor 1(FGFR1) and Klotho colocalize. The FGFR1 has three immunoglobulin (Ig)-like domains. Klotho forms complex with FGFR1 and serves as the high-affinity receptor for FGF23. Klotho has a negligible intracellular region, whereas the FGFR1 has two kinase domains that sustain signal transduction [reprinted with permission from 26].

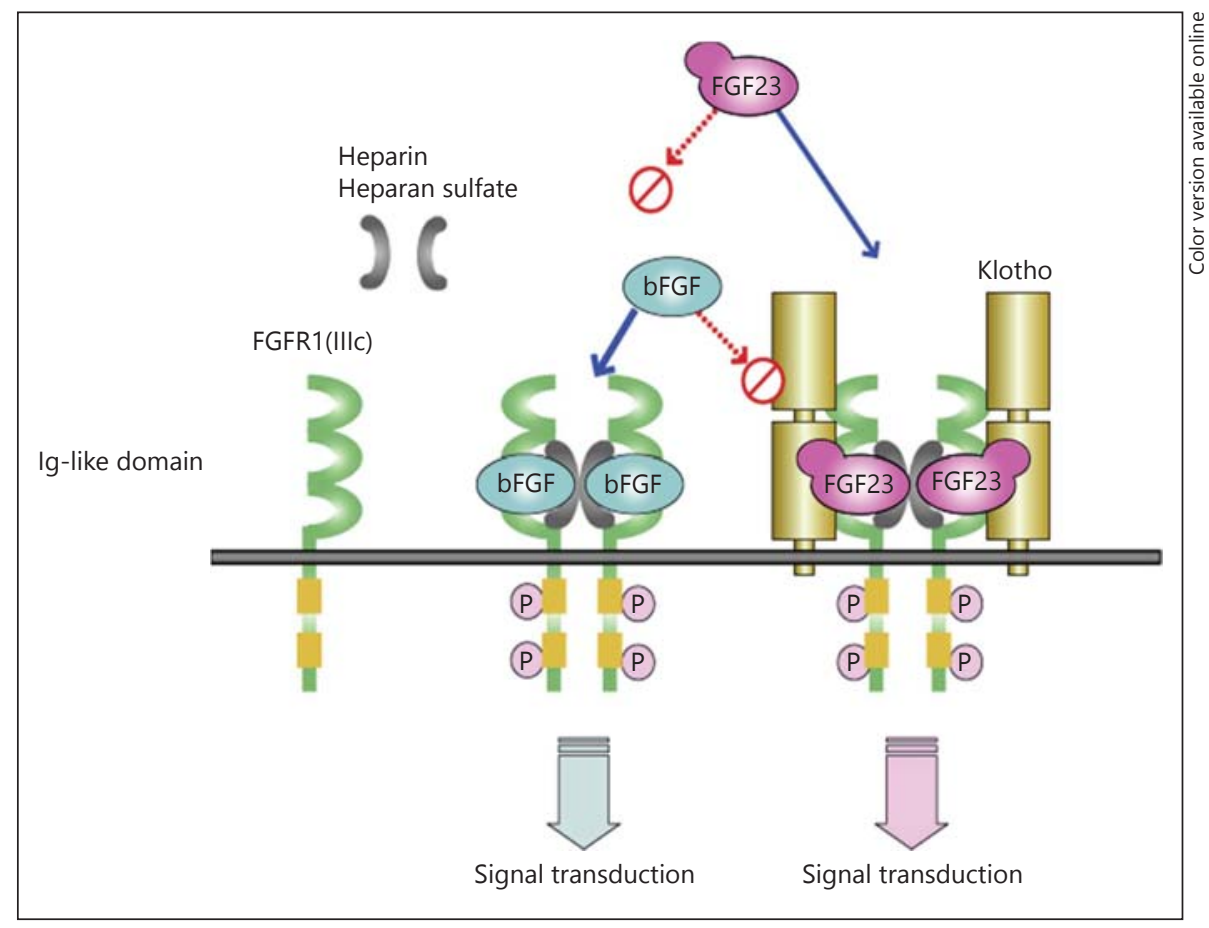

Both Klotho and FGFR are expressed in the parathyroid glands, suggesting the possibility that FGF23 regulates PTH secretion. In support of this possibility, data obtained in vitro suggest that FGF23 decreases PTH mRNA transcription and protein secretion in a dose-dependent manner [30]. Conversely, because rodents with primary hyperparathyroidism have increased FGF23 levels that are reduced by parathyroidectomy, PTH may stimulate FGF23 secretion by osteoblasts [31]. In physiological settings in which there is normal Klotho and FGFR expression, FGF23 decreases PTH production, increases expression of both the parathyroid Ca-sensing receptor and the vitamin D receptor, and decreases cell proliferation [32].

\section{Function of Soluble Klotho}

Alternative splicing is not the only mechanism by which soluble Klotho is produced, because Klotho is subjected to ectodomain shedding and its entire extracellular domain is secreted into blood, urine, and cerebrospinal fluid [33], thereby enabling it to function as a humoral factor independently of FGF23 [34]. Klotho is cleaved on the cell surface by membrane-anchored proteases, including by a desintegrin and metalloproteinase (ADAM)10, and by ADAM-17 [35]. Thus far, only Klotho has been shown to be released from the cells into plasma [29], cerebrospinal fluid [33], and urine [36]. The plasma concentration of $\alpha$-Klotho is approximately $10-50 \mathrm{nM}$, and its urine concentrations are higher [36].

Secreted Klotho has a putative sialidase activity that removes the terminal sialic acids from the N-linked glycans of several glycoproteins on the cell surface [37]. Secreted Klotho prevents endocytosis of transient receptor potential cation channel, subfamily $\mathrm{V}$, member 5 (TRPV5) $[37,38]$ and renal outer medullary potassium channel 1 (ROMK1) by modifying their N-linked glycans on the cell surface, thereby resulting in an increase in Ca currents. By contrast, secreted Klotho promotes endocytosis and inactivation of NaPi-IIa by modifying its glycans [29]. Secreted Klotho also suppresses the activity of insulin, insulin-like growth factor-1 [34], Wnt [39], and transforming growth factor- $\beta_{1}[40]$ by interacting with them or with their receptors. The physiological significance of these pleiotropic activities of secreted Klotho remains to be determined.

\section{Role of FGF23 in Mineral Metabolism in CKD}

Patients with stages 4-5 CKD and dialysis patients often develop hyperphosphatemia due to impaired renal $\mathrm{P}$ excretion. The impaired renal $\mathrm{P}$ excretion is the result of 
the decrease in number of intact nephrons. In addition to the reduced kidney function, the increase in FGF23 level contribute to the decrease in serum $1,25(\mathrm{OH})_{2} \mathrm{D}$ concentration in CKD and a subsequent increase in PTH secretion to maintain normal serum Ca levels, but it also induces a high turnover bone [41]. An increased production of FGF23 by bone may not be responsible for early increase in FGF23 in CKD but does appear to contribute to FGF23 levels in late stage of CKD [42]. Elevation in FGF23 and PTH coincide with an increase in FePi that likely prevents the early onset of hyperphosphatemia in the face of increased bone turnover and a progressive decline in functional renal mass.

Since it has been reported that serum FGF23 levels increase as renal function declines $[43,44]$ and that the circulating FGF23 levels of CKD patients gradually increase with declining renal function [21], it has been hypothesized that the increased serum FGF23 levels in CKD are primarily the result of decreased renal clearance. Larsson et al. [45] showed that FGF23 levels did not change after $\mathrm{P}$ deprivation or $\mathrm{P}$ loading in healthy subjects during 6-day observation. By contrast, no associations between serum FGF23 levels and GFR have been found in the earlier stages of CKD, when patients are normophosphatemic [45]. The hyperphosphatemia associated with CKD most likely triggers FGF23 production, which promotes renal $P$ excretion, reflected by the greatly elevated FGF23 levels in CKD conditions [43]. It has recently been recognized that serum FGF23 levels increase before the elevation in serum levels of $\mathrm{P}$ and PTH in CKD patients [46].

The cause of the increased FGF23 levels in CKD patients is still under investigation. Instead of decreased renal clearance in CKD patients, there may be end-organ resistance to the phosphaturic action of FGF23 because of a deficiency of Klotho, the required cofactor. Koh et al. [47] detected significantly reduced Klotho mRNA expression in kidney biopsy specimens from CKD patients. The higher FGF23 levels in CKD patients may reflect the operation of a physiological compensatory mechanism that stabilizes serum $\mathrm{P}$ levels as the number of intact nephrons declines. FGF23 induces phosphaturia and lowers serum $P$ level through reduction and internalization of the NaPi-IIa and $\mathrm{NaPi}$-IIc in the proximal tubules [48]. Furthermore, FGF23 directly suppresses renal $1 a$-hydroxylase expression, leading to decreased conversion of 25-hydroxyvitamin $\mathrm{D}$ to its active metabolite $1,25(\mathrm{OH})_{2} \mathrm{D}[48]$.

FGF23 has been found to decrease serum PTH and parathyroid PTH mRNA levels in vivo in short-term experiments [32]. The experiments showed that FGF23 suppressed both PTH secretion and PTH gene expression directly, because Klotho is present on parathyroid cells in addition to FGFR. There are in vivo animal models of FGF23 overexpression, and all of them are characterized by parathyroid hyperplasia and increased PTH levels [49]. Because the suppressed $1,25(\mathrm{OH})_{2} \mathrm{D}$ levels would lead to persistent hypocalcemia, a more likely explanation of the increase in PTH levels and parathyroid hyperplasia observed in these animals is that they are mediated by the $\mathrm{Ca}-$ sensing receptor, again protecting systemic Ca levels. Indeed, mice expressing high systemic levels of FGF23 (R176Q) exhibit hypocalcemia and subsequently develop secondary hyperparathyroidism, even though their elevated PTH levels are likely to aggravate the prevailing hypophosphatemia [50].

\section{Role of Klotho Deficiency in CKD}

If the organ that is the source of an endocrine substance is diseased, it is logical to suspect that an endocrine deficiency of that substance will ensue. There are many similarities between the clinical manifestations of CKD and the phenotype of $\mathrm{Klotho}^{-/-}$mice. Experimental data from in vivo and in vitro studies and clinical findings have by and large supported this view [46, 51-55].

Measurements of renal Klotho mRNA and protein in human CKD have been limited. Renal expression of the Klotho gene is markedly decreased in patients with CKD of different etiologies $[46,56]$. Data on the plasma Klotho levels of CKD patients have begun to emerge as a result of the use of a recently developed ELISA [57]. The initial data showed that the plasma Klotho levels of CKD patients inversely correlated with their serum creatinine, blood urea nitrogen, and FGF23 levels, suggesting that plasma Klotho levels may be affected by renal function, even though that this study did not enroll any CKD patients [57]. More recent studies have shown that soluble plasma Klotho levels were found to be decreased in CKD patients than the levels of healthy volunteers [58-60]. However, controversial data were reported that the soluble Klotho levels were significantly associated with age, but not GFR or other parameters of Ca-P metabolism in patients with stage 2-4 CKD [61]. Moreover, while patients with higher plasma FGF23 levels but not soluble Klotho levels faced event-free survival even after adjustment for confounders [61]. Further studies are needed to determine whether plasma levels of soluble Klotho may be a significant predictor for adverse outcomes in CKD patients. 
The urinary Klotho levels of CKD patients have been shown to decrease in the very early stages of CKD and to remain low as CKD progresses [36]. In a rodent CKD model, Klotho levels in plasma, urine, and kidney were shown to decrease in parallel [36], but the relationship between their levels in CKD patients remains to be determined. Furthermore, almost all models of CKD, including models that have been created by renal tissue ablation, glomerulonephritis, nephrotoxin, diabetic nephropathy, and hypertensive kidney damage, are characterized by considerable downregulation of Klotho mRNA and protein in the kidney and by low plasma or urine-soluble Klotho levels [62]. Plasma soluble Klotho levels are also decreased in the early stages of CKD [58]. Pavik et al. [63] have reported finding that soluble Klotho and $1,25(\mathrm{OH})_{2} \mathrm{D}$ levels decrease and FGF23 levels increase in the early stages of CKD, and that PTH levels increase in the more advanced stages. Akimoto et al. [64] have recently shown that the urinary Klotho levels of CKD patients, rather than their serum Klotho levels, are linked to their number of functioning nephrons. Sakan et al. [65] recently reported that although renal $\alpha$-Klotho levels were significantly reduced and serum FGF23 levels were significantly elevated in early and intermediate $C K D$, serum $P$ levels remained within the normal range. Despite falling renal a-Klotho levels, the increase in FGF23 enhanced urinary FePi and reduced serum 1,25(OH)2D levels in early and intermediate CKD, though not in advanced CKD. In addition, serum-soluble Klotho levels fell significantly over the course of CKD, and renal $\alpha$-Klotho expression was a significant independent determinant of soluble Klotho. These results indicate that FGF23 levels rise to compensate for renal failure-related $\mathrm{P}$ retention in early and intermediate CKD. This enables FGF23-Klotho signaling and a neutral $\mathrm{P}$ balance to be maintained despite the reduction in $\alpha$-Klotho expression. The presumed changes in plasma FGF23, Klotho, $\mathrm{PTH}$, active vitamin $\mathrm{D}$, and $\mathrm{P}$ levels in the course of CKD stage progression have been advocated in figure 5 [62]. However, there is a possibility that the time-course change of plasma Klotho in this figure would rather reflect the change of renal Klotho expression.

\section{Role of FGF23 and Klotho in Vascular Calcification}

Cardiovascular disease is a leading cause of mortality in $\mathrm{CKD}$, and cardiovascular calcification is common in the cardiovascular disease of CKD patients $[66,67]$. Cardiovascular calcification is a heterogeneous disorder with

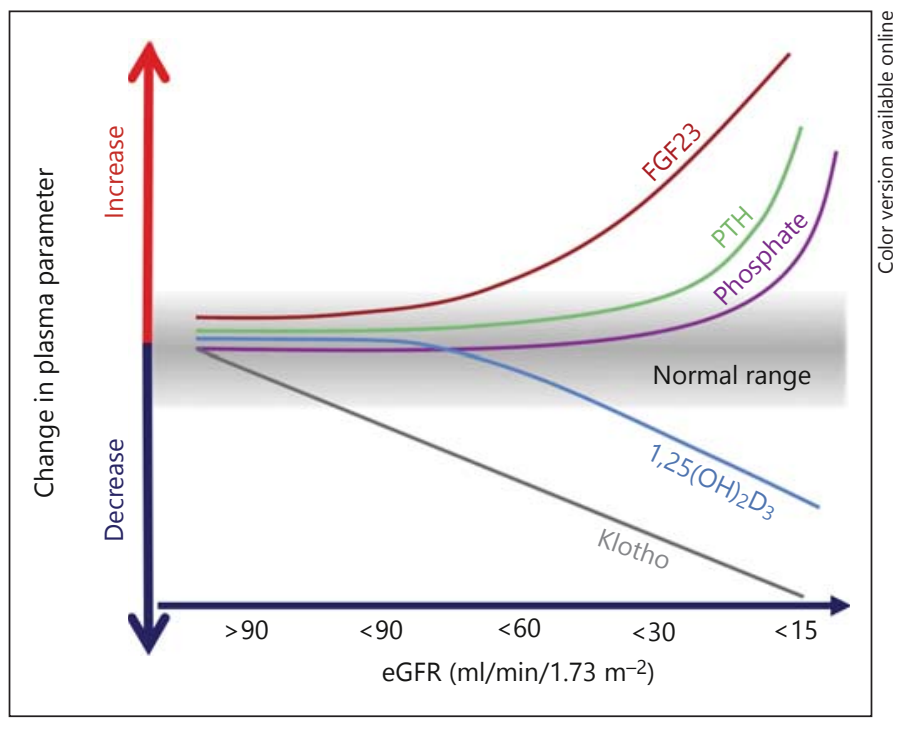

Fig. 5. Time profile of changes in plasma FGF23, Klotho, active vitamin $\mathrm{D}$, and phosphate levels as CKD progresses. The decrease in Klotho protein in the blood is an early event in CKD and is progressively reduced along with the decline of renal function. Low Klotho partially induces FGF23 resistance, causing an initial compensatory increase in blood FGF23 to maintain P homeostasis. The increase in FGF23 decreases active vitamin D levels and is followed by elevation of PTH. Hyperphosphatemia is relatively late event in advanced CKD [reprinted with permission from 60].

overlapping distinct mechanisms of initiation and progression $[68,69]$. Vascular calcification is a dynamic process that results from an imbalance between promoters and inhibitors [67, 70]. FGF23 and Klotho are recently recognized contributors to ectopic calcification in soft tissues, including in cardiac valves and the aorta $[23,36,71]$. Severe bone loss has been found to be associated with medial calcifications in the aorta of rats with CKD induced by adenine and a high protein diet [72]. The discovery of a stronger correlation between cortical bone loss than trabecular bone loss and the severity of vascular calcification in CKD rats is an intriguing finding [72]. It has been proposed that Ca release from disturbed bone tissue in accordance with low $1,25(\mathrm{OH})_{2} \mathrm{D}$, high FGF23, and low soluble Klotho may trigger or accelerate vascular calcification [72].

Vascular calcification is a prominent finding in mice with a Klotho gene deletion, the same as in CKD patients. The vascular calcification observed in $\mathrm{Klotho}^{-1-}$ mice is reversed by the Klotho overexpression that results from adenoviral delivery of the Klotho gene [73]. Recombinant Klotho protein suppresses the NaPi-III transporter Pit1 expression and $\mathrm{P}$ uptake induced by a high-P medium in 
rat vascular smooth cells [36]. The mechanism of the suppressive influence of Klotho on vascular calcification is multifactorial and includes the indirect effect of phosphaturia, and Klotho has direct effects on the vasculature that are independent of its systemic effects. High P uptake induces vascular smooth muscle cell reprogramming to osteoblasts/osteochondrocytes through the Pit-1 and/or Pit-2, and Klotho inhibits the reprogramming [74]. Klotho also prevents the cell senescence, apoptosis, and death of vascular endothelial cells and smooth muscle cells that are induced by a variety of insults, including $\mathrm{P}$ overload [75, 76]. Finally, Klotho is an anti-inflammatory modulator and restricts the inflammatory process in a way that protects the vasculature [54]. All of these experiments in which Klotho was directly added in vitro were performed in the absence of FGF23.

There is controversy regarding whether FGF23 is a contributor to vascular calcification. Lim et al. [77] have proposed that CKD is a state of vascular Klotho deficiency that potentiates the development of accelerated calcification via a Runx2- and myocardin-serum response factor-dependent pathway. Since Klotho knockdown has been shown to abrogate FGF23-mediated cell signaling and proliferative effects, vascular cells may be a Klothodependent target tissue for FGF23. Restoration of Klotho and FGFRs by vitamin $\mathrm{D}$ receptor activators renders human vascular smooth muscle cells FGF23-responsive, and that may be the mechanism of the anticalcific effects [77]. Scialla et al. [78] have recently reported finding that the baseline plasma FGF23 level is not associated with the prevalence or severity of coronary artery Ca content after multivariable adjustment among 1,501 patients in the Chronic Renal Insufficiency Cohort (CRIC) study, suggesting that FGF23 is not associated with arterial calcification and does not promote arterial calcification. In addition, the results of in vitro study clearly showed that FGF23 does not induce vascular calcification. Finally, Lindberg et al. [79] did not support Klotho-mediated FGF23 effects in the vasculature because of absence of FGF23-Klotho signaling in mouse arteries. Further studies are needed to investigate the precise role of KlothoFGF23 interaction in vascular calcification.

\section{Future Prospects}

There are still two remaining issues in terms of pathological conditions in CKD: high FGF23 and low Klotho. Pharmacological or peptide blockade of FGF23 is being assessed as treatments for CKD-MBD in the preclinical stage $[80,81]$. The use of anti-FGF23 monoclonal antibodies as a treatment for CKD-MBD is based on the hypothesis that high FGF23 levels are detrimental in CKD. The short-term neutralization of FGF23 increases serum $\mathrm{P}, \mathrm{Ca}$, and $1,25(\mathrm{OH})_{2} \mathrm{D}$ levels and decreases PTH levels in $\mathrm{CKD}$ rats [82]. On the contrary, the long-term neutralization of FGF23 in CKD rats improves high turnover bone histology but accelerates vascular calcification and increases mortality, indicating that while high serum FGF23 levels may be harmful, complete removal of FGF23 for prolonged period does not solve the problem [83]. Even though high serum FGF23 levels are associated with cardiovascular events and all-cause mortality, it is unknown whether these associations differ by the degree of phosphaturia. Dominquez et al. [84] have recently reported that the associations of FGF23 with cardiovascular events and mortality are stronger in normal to moderate CKD patients with lower FePi independent of PTH and GFR. Concurrent measurement of FGF 23 and FePi may provide a noninvasive index of kidney tubule resistance to FGF23 phosphaturic effect (i.e. renal Klotho expression levels).

Treatment CKD patients with exogenous recombinant Klotho protein is a simple and effective means of correcting Klotho deficiency, similar to the replacement of erythropoietin and active vitamin D. Klotho administration has proved to be protective against acute kidney injury in animal studies, which is a state of acute Klotho deficiency induced by ischemia-reperfusion injury [85, 86] and by unilateral ureteral ligation [40], and also in $\mathrm{CKD}$ in mice with systemic and renal Klotho deficiency induced by unilateral nephrectomy and contralateral ischemia-reperfusion [36]. Klotho may also reverse or retard the progression of CKD. Even in the advanced stages of CKD, Klotho supplementation may alleviate the extrarenal complications of CKD. Stimulation or reversal of suppression of endogenous Klotho production may be an alternative means of increasing Klotho replacement in the kidney. Finally, possible future strategies to increase the extrarenal Klotho production are of interest as a means of treating end-stage renal disease patients. Thus, possible strategies that can be used to increase endogenous Klotho include control of hyperphosphatemia [87], vitamin D repletion [24], and angiotensin II blockade [88].

\section{Disclosure Statement}

The authors have no conflicts of interest to disclose. 


\section{References}

1 Sarnak M, Levey A, Schoolwerth A, Coresh J, Culleton B, Hamm LL, et al: Kidney disease as a risk factor for development of cardiovascular disease: a statement from the American Heart Association Councils on kidney in cardiovascular disease, high blood pressure research, and epidemiology and prevention. Circulation 2003;108:2154-2169.

$\checkmark 2$ Weiner DE, Tighiouart H, Amin MG, Stark PC, MacLeod B, Griffith JL, et al: Chronic kidney disease as a risk factor for cardiovascular disease and all-cause mortality: a pooled analysis of community-based studies. J Am Soc Nephrol 2004;15:1307-1315.

-3 Go AS, Chertow GM, Fan D, McCulloch CE, Hsu CY: Chronic kidney disease and the risks of death, cardiovascular events, and hospitalization. N Engl J Med 2004;351: 1296-1305.

-4 Kidney Disease: Improving Global Outcomes (KDIGO) CKD-MBD Work Group: KDIGO clinical practice guideline for the diagnosis, evaluation, prevention, and treatment of chronic kidney disease-mineral and bone disorder (CKD-MBD). Kidney Int Suppl 2009; 113:S1-S130.

5 Yamashita T, Yoshioka M, Itoh N: Identification of a novel fibroblast growth factor, FGF23, preferentially expressed in the ventrolateral thalamic nucleus of the brain. Biochem Biophys Res Commun 2000;277:494498.

6 Riminucci M, Collins MT, Fedarko NS, Cherman N, Corsi A, White KE, et al: FGF-23 in fibrous dysplasia of bone and its relationship to renal phosphate wasting. J Clin Invest 2003; 112:683-692.

-7 Pereira RC, Juppner H, Azucena-Serrano CE, Yadin O, Salusky IB, Wesseling-Perry K: Patterns of FGF-23, DMP1, and MEPE expression in patients with chronic kidney disease. Bone 2009;45:1161-1168.

8 Yamashita T: Structural and biochemical properties of fibroblast growth factor 23. Ther Apher Dial 2005;9:313-318.

$\checkmark$ Quarles LD: Endocrine functions of bone in mineral metabolism regulation. J Clin Invest 2008; 118:3820-3828.

10 Bai XY, Miao D, Goltzman D, Karaplis AC: The autosomal dominant hypophosphatemic rats R176Q mutation in fibroblast growth factor 23 resists proteolytic cleavage and enhances in vivo biological potency. J Biol Chem 2003;278:9843-9849.

-11 Larsson T, Marsell R, Shipani E, Ohlsson C, Ljunggren O, Tenenhouse HS, et al: Transgenic mice expressing fibroblast growth factor 23 under the control of the a1(I) collagen promoter exhibit growth retardation, osteomalacia, and disturbed phosphate homeostasis. Endocrinology 2004;145:3087-3094.

-12 Shimada T, Urakawa I, Yamazaki Y, Hasegawa H, Hino R, Yoneya T, et al: FGF23 transgenic mice demonstrate hypophosphatemic rickets with reduced expression of sodium phosphate cotransporter type IIa. Biochem Biophys Res Commun 2004;314:409-414.

13 Bai X, Miao D, Li J, Goltzman D, Karaplis AC: Transgenic mice overexpressing human fibroblast growth factor 23 (R176Q) delineate a putative role for parathyroid hormone in renal phosphate wasting disorders. Endocrinology 2004;145:5269-5279.

14 Segawa H, Kawakami E, Kaneko I, Kuwahata M, Ito M, Kusano K, et al: Effect of hydrolysis-resistant FGF23-R179Q on dietary phosphate regulation of the renal type II $\mathrm{Na} / \mathrm{Pi}$ transporter. Pflugers Arch 2003;446:585592.

15 Shimada T, Hasegawa H, Yamazaki Y, Muto T, Hino R, Takeuchi Y, et al: FGF23 is a potent regulator of the vitamin $\mathrm{D}$ metabolism and phosphate homeostasis. J Bone Miner Res 2004;19:429-435.

16 Sitara D, Razzaque MS, Hesse M, Yoganathan S, Taguchi T, Erben RG, et al: Homozygous ablation of fibroblast growth factor-23 results in hyperphosphatemia and impaired skeletogenesis, and reverse hypophosphatemia in Phex-deficient mice. Matrix Biol 2004;23: 421-432.

17 Shimada T, Kakitani M, Yamazaki Y, Hasegawa H, Takeuchi Y, Fujita T, et al: Targeted ablation of Fgf23 demonstrates an essential physiological role of FGF23 in phosphate and vitamin D metabolism. J Clin Invest 2004; 113:561-568.

18 Khosravi A, Cutler CM, Kelly MH, Chang R, Royal RE, Sherry RM, et al: Determination of the elimination half-life of fibroblast growth factor-23. J Clin Endocrinol Metab 2007;92: 2374-2377.

19 Yamazaki Y, Okazaki R, Shibata M, Hasegawa Y, Satoh K, Tajima T, et al: Increased circulatory level of biologically active full-length FGF-23 in patients with hypophosphatemic rickets/osteomalacia. J Clin Endocrinol Metab 2002;87:4957-4960.

20 Ibrahim S, Rashed L: Serum fibroblast growth factor-23 levels in chronic haemodialysis patients. Int Urol Nephrol 2009;41:163-169.

21 Gutierrez O, Isakova T, Rhee E, Shah A, Holmes J, Collerone G, et al: Fibroblast growth factor-23 mitigates hyperphosphatemia but accentuates calcitriol deficiency in chronic kidney disease. J Am Soc Nephrol 2005; 16:2205-2215.

22 Isakova T, Xie H, Yang W, Xie D, Anderson AH, Scialla J, et al: Fibroblast growth factor 23 and risks of mortality and end-stage renal disease in patients with chronic kidney disease. JAMA 2011;305:2432-2439.

23 Kuro-o M, Matsumura Y, Aizawa H, Kawaguchi H, Suga T, Utsugi T, et al: Mutation of the mouse klotho gene leads to a syndrome resembling ageing. Nature 1997;390:45-51.

24 Tsujikawa H, Kurotaki Y, Fujimori T, Fukuda K, Nabeshima Y: Klotho, a gene related to a syndrome resembling human premature ageing, functions in a negative regulatory circuit of vitamin D endocrine system. Mol Endocrinol 2003;17:2393-2403.

25 Kurosu H, Ogawa Y, Miyoshi M, Yamamoto M, Nandi A, Rosenblatt KP, et al: Regulation of fibroblast growth factor-23 signaling by klotho. J Biol Chem 2006;281:6120-6123.

26 Urakawa I, Yamazaki Y, Shimada T, Iijima K, Hasegawa H, Okawa K, et al: Klotho converts canonical FGF receptor into a specific receptor for FGF23. Nature 2006;444:770-774.

27 Lau WL, Leaf EM, Hu MC, Takeno MM, Kuro-o M, Moe OW, et al: Vitamin D receptor agonists increase klotho and osteopontin while decreasing aortic calcification in mice with chronic kidney disease fed a high phosphate diet. Kidney Int 2012;82:12611270.

28 Farrow EG, Davis SI, Summers LJ, White KE: Initial FGF23-mediated signaling occurs in the distal convoluted tubule. J Am Soc Nephrol 2009;20:955-960.

29 Hu MC, Shi M, Zhang J, Pastor J, Nakatani T, Lanske B, et al: Klotho: a novel phosphaturic substance acting as an autocrine enzyme in the renal proximal tubule. FASEB J 2010;24: 3438-3450.

30 Krajisnik T, Björklund P, Marsell R, Ljunggren $\mathrm{O}$, Akerstrom $\mathrm{G}$, Jonsson $\mathrm{KB}$, et al: Fibroblast growth factor-23 regulates parathyroid hormone and 1-hydroxylase expression in cultured bovine parathyroid cells. J Endocrinol 2007;195:125-131.

31 Kawata T, Imanishi Y, Kobayashi K, Miki T, Arnold $\mathrm{A}$, Inaba $\mathrm{M}$, et al: Parathyroid hormone regulates fibroblast growth factor-23 in a mouse model of primary hyperparathyroidism. J Am Soc Nephrol 2007; 18:2683-2688.

32 Ben-Dov IZ, Galitzer H, Lavi-Moshayoff V, Goetz R, Kuro-o M, Mohammadi M, et al: The parathyroid is a target organ for FGF23 in rats. J Clin Invest 2007;117:4003-4008.

- 33 Imura A, Iwano A, Tohyama O, Tsuji Y, Nozaki K, Hashimoto N, Fujimori T, et al: Secreted Klotho protein in sera and CSF: implication for post-translational cleavage in release of Klotho protein from cell membrane. FEBS Lett 2004;565:143-147.

34 Kurosu H, Yamamoto M, Clark JD, Pastor JV, Nandi A, Gurnani P, et al: Suppression of aging in mice by the hormone Klotho. Science 2005;309:1829-1833.

35 Chen CD, Podvin S, Gillespie E, Leeman SE, Abraham CR: Insulin stimulates the cleavage and release of the extracellular domain of Klotho by ADAM10 and ADAM17. Proc Natl Acad Sci USA 2007;104:19796-19801.

$36 \mathrm{Hu}$ MC, Shi M, Zhang J, Quinones H, Griffith C, Kuro-o M, et al: Klotho deficiency causes vascular calcification in chronic kidney disease. J Am Soc Nephrol 2011;22:124-136.

- 37 Cha SK, Ortega B, Kurosu H, Rosenblatt KP, Kuro-o M, Huang CL: Removal of sialic acid involving Klotho causes cell-surface retention of TRPV 5 channel via binding to galectin-1. Proc Natl Acad Sci USA 2008;105:9805-9810. 
-38 Chang Q, Hoefs S, van der Kemp AW, Topala CN, Bindels RJ, Hoenderop JG: The $\beta$-glucuronidase klotho hydrolyzes and activates the TRPV5 channel. Science 2005;310: 490-493.

- 39 Liu H, Fergusson MM, Castilho RM, Liu J, Cao L, Chen J, et al: Augmented Wnt signaling in a mammalian model of accelerated aging. Science 2007;317:803-806.

40 Doi S, Zou Y, Togao O, Pastor JV, John GB, Wang $L$, et al: Klotho inhibits transforming growth factor- $\beta_{1}$ (TGF- $\left.\beta_{1}\right)$ signaling and suppresses renal fibrosis and cancer metastasis in mice. J Biol Chem 2011;286:86558665.

41 Cozzolino M, Galassi A, Galliei M, Brancaccio D: Pathogenesis and treatment of secondary hyperparathyroidism in dialysis patients: the role of paricalcitol. Curr Vasc Pharmacol 2008;6:148-153.

-42 Stubbs JR, He N, Idiculla A, Gillihan R, Liu S, David V, et al: Longitudinal evaluation of FGF23 changes and mineral metabolism abnormalities in a mouse model of chronic kidney disease. J Bone Miner Res 2012;27:38-46.

43 Nagano N, Miyata S, Abe M, Kobayashi N, Wakita S, Yamashita T, et al: Effect of manipulating serum phosphorus with phosphate binder on circulating PTH and FGF23 in renal failure rats. Kidney Int 2006;69:531-537.

-44 Fliser D, Kollerits B, Neyer U, Ankerst DP, Lhotta K, Lingenhel A, et al: Fibroblast growth factor 23 (FGF23) predicts progression of chronic kidney disease: the Mild to Moderate Kidney Disease (MMKD) Study. J Am Soc Nephrol 2007;18:2600-2608.

-45 Larsson T, Nisbeth U, Ljunggren O, Juppner $\mathrm{H}$, Jonsson KB: Circulating concentration of FGF-23 increases as renal function declines in patients with chronic kidney disease, but does not change in response to variation in phosphate intake in healthy volunteers. Kidney Int 2003;64:2272-2279.

-46 Nakano C, Hamano T, Fujii N, Obi Y, Matsui I, Tomida K, et al: Combined use of vitamin D status and FGF23 for risk stratification of renal outcome. Clin J Am Soc Nephrol 2012; 7:810-819.

-47 Koh N, Fujimori T, Nishiguchi S, Tamori A, Shiomi S, Nakatani T, et al: Severely reduced production of klotho in human chronic renal failure kidney. Biochem Biophys Res Commun 2001;280:1015-1020.

-48 Seiler S, Heine GH, Fliser D: Clinical relevance of FGF-23 in chronic kidney disease. Kidney Int Suppl 2009;114:S34-S42.

49 Lavi-Moshayoff V, Silver J, Naveh-Many T: Human PTH gene regulation in vivo using transgenic mice. Am J Physiol Renal Physiol 2009;297:F713-F719.

-50 Razzaque MS, Lanske B: The emerging role of the fibroblast growth factor-23-klotho axis in renal regulation of phosphate homeostasis. J Endocrinol 2007;194:1-10.

-51 Haruna Y, Kashihara N, Satoh M, Tomita N, Namikoshi T, Sasaki T, et al: Amelioration of progressive renal injury by genetic manipula- tion of Klotho gene. Proc Natl Acad Sci U S A 2007; 104:2331-2336.

52 Wang Y, Sun Z: Klotho gene delivery prevents the progression of spontaneous hypertension and renal damage. Hypertension 2009;54: 810-817.

$53 \mathrm{Hu}$ MC, Kuro-o M, Moe OW: Klotho and kidney disease. J Nephrol 2010;23(suppl 16): S136-S144.

54 Zhao Y, Banerjee S, Dey N, LeJeune WS, Sarkar PS, Brobey R, et al: Klotho depletion contributes to increased inflammation in kidney of the $\mathrm{db} / \mathrm{db}$ mouse model of diabetes via RelA (serine) 536 phosphorylation. Diabetes 2011;60:1907-1916.

$55 \mathrm{Hu}$ MC, Kuro-o M, Moe OW: Secreted klotho and chronic kidney disease. Adv Exp Med Biol 2012;728:126-157.

56 Asai O, Nakatani K, Tanaka T, Sakan H, Imura $\mathrm{A}$, Yoshimoto $\mathrm{S}$, et al: Decreased renal a-Klotho expression in early diabetic nephropathy in humans and mice and its possible role in urinary calcium excretion. Kidney Int 2012;81:539-547.

57 Yamazaki Y, Imura A, Urakawa I, Shimada T, Murakami J, Ando Y, et al: Establishment of sandwich ELISA for soluble $\alpha$-Klotho measurement: age-dependent change of soluble a-Klotho levels in healthy subjects. Biochem Biophys Res Commun 2010;398:513-518.

58 Shimamura Y, Hamada K, Inoue K, Ogata K, Ishihara M, Kagawa T, Inoue M, et al: Serum levels of soluble $\alpha$-Klotho are decreased in the early stages of chronic kidney disease, making it a probable novel biomarker for early diagnosis. Clin Exp Nephrol 2012;16:722-729.

59 Gutierrez OM, Ix JH: $\alpha$-Klotho and kidney function decline: an important step forward in understanding the link between mineral metabolism and kidney disease progression. Am J Kidney Dis 2013;61:855-857.

60 Kim HR, Nam BY, Kim DW, Kang MW, Han $\mathrm{JH}$, Lee MJ, et al: Circulating $\alpha$-klotho levels in CKD and relationship to progression. Am J Kidney Dis 2013;61:899-909.

61 Seiler S, Wen M, Roth HJ, Fehrenz M, Flügge F, Herath E, et al: Plasma Klotho is not related to kidney function and does not predict adverse outcome in patients with chronic kidney disease. Kidney Int 2013;83:121-128.

$62 \mathrm{Hu}$ MC, Shiizaki K, Kuro-o M, Moe OW: Fibroblast growth factor 23 and Klotho: physiology and pathophysiology of an endocrine network of mineral metabolism. Annu Rev Physiol 2013;75:503-533.

63 Pavik I, Jaeger P, Ebner L, Wahner CA, Petzold K, Spichtig D, et al: Secreted Klotho and FGF23 in chronic kidney disease stages 1 to 5 : a sequence suggested from a cross-sectional study. Nephrol Dial Transplant 2013;28:352359.

64 Akimoto T, Yoshizawa $\mathrm{H}$, Watanabe $\mathrm{Y}, \mathrm{Nu}-$ mata A, Yamazaki T, Takeshima E, et al: Characteristics of urinary and serum soluble Klotho protein in patients with different degrees of chronic kidney disease. BMC Nephrol 2012;13:155.
65 Sakan H, Nakatani K, Asai O, Imura A, Tana$\mathrm{ka} T$, Yoshimoto $\mathrm{S}$, et al: Reduced renal a-Klotho expression in CKD patients and its effect on renal phosphate handling and vitamin D metabolism. PLoS One 2014;9:e86301.

66 Coresh J, Astor B, Sarnak MJ: Evidence for increased cardiovascular disease risk in patients with chronic kidney disease. Curr Opin Nephrol Hypertens 2004;13:73-81.

67 Kendrick J, Chonchol MB: Nontraditional risk factors for cardiovascular disease in patients with chronic kidney disease. Nat Clin Pract Nephrol 2008;4:672-681.

68 Moe SM, Chen NX: Mechanisms of vascular calcification in chronic kidney disease. J Am Soc Nephrol 2008;19:213-216.

69 Cannata-Andia JB, Rodriguez-Garcia M, Carrillo-Lopez N, Naves-Diaz M, Diaz-Lopez B: Vascular calcifications: pathogenesis, management, and impact on clinical outcomes. J Am Soc Nephrol 2006;17(suppl 3):S267-S273.

70 Nitta K: Vascular calcification in patients with chronic kidney disease. Ther Apher Dial 2011;15:513-521.

71 Nakatani T, Sarraj B, Ohnishi M, Densmore MJ, Taguchi T, Goetz R, et al: In vivo genetic evidence for klotho-dependent, fibroblast growth factor 23 (Fgf23)-mediated regulation of systemic phosphate homeostasis. FASEB J 2009;23:433-441.

72 De Schutter TM, Neven E, Persy VP, Behets GJ, Postnov AA, Clerck NM, et al: Vascular calcification is associated with cortical bone loss in chronic renal failure rats with and without ovariectomy: the calcification paradox. Am J Nephrol 2011;34:356-366.

73 Shiraki-Iida T, Iida A, Nabeshima Y, Anazawa $\mathrm{H}$, Nishikawa S, Noda M, et al: Improvement of multiple pathophysiological phenotypes of klotho $(k l / k l)$ mice by adenovirusmediated expression of the klotho gene. J Gene Med 2000;2:233-242.

74 Lau WL, Festing MH, Giachelli CM: Phosphate and vascular calcification: emerging role of the sodium-dependent phosphate cotransporter PiT-1. Thromb Haemost 2010; 104:464-470

75 De Oliveira RM: Klotho RNAi induces premature senescence of human cells via a p53/ p21-dependent pathway. FEBS Lett 2006;580: 5753-5758.

76 Nakano-Kurimoto R, Ikeda K, Uraoka M, Nakagawa Y, Yutaka K, Koide M, et al: Replicative senescence of vascular smooth muscle cells enhances the calcification through initiating the osteoblastic transition. Am J Physiol Heart Circ Physiol 2009;297:H1673-H1684.

77 Lim K, Lu TS, Molostvov G, Lee C, Lam FT, Zehnder D, et al: Vascular Klotho deficiency potentiates the development of human artery calcification and mediates resistance to FGF23. Circulation 2012;125:2243-2255.

78 Scialla JJ, Lau WL, Reilly MO, Isakova T, Yang HY, Crouthamel MH, et al: Fibroblast growth factor 23 is not associated with and does not induce arterial calcification. Kidney Int 2013; 83:1159-1168. 
79 Lindberg K, Olauson H, Amin R, Ponnusamy A, Goetz R, Taylor RF, et al: Arterial klotho expression and FGF23 effects on vascular calcification and function. PLoS One 2013;8: e60658.

80 Goetz R, Nakada Y, Hu MC, Kurosu H, Wang L, Nakatani T, et al: Isolated C-terminal tail of FGF23 alleviates hypophosphatemia by inhibiting FGF23-FGFR-Klotho complex formation. Proc Natl Acad Sci U S A 2010;107: 407-412.

81 Razzaque MS: Therapeutic potential of klothoFGF23 fusion polypeptides: WO2009095372. Expert Opin Ther Pat 2010;20:981-985.
82 Hasegawa H, Nagano N, Urakawa I, Yamazaki Y, Iijima K, Fujita T, et al: Direct evidence for a causative role of FGF23 in the abnormal renal phosphate handling and vitamin D metabolism in rats with early-stage chronic kidney disease. Kidney Int 2010;78:975-980.

83 Shalhoub V, Shatzen EM, Ward SC, Davis J, Stevens J, Bi V, et al: FGF23 neutralization improves secondary hyperparathyroidism and osteodystrophy parameters yet exacerbates vascular calcification in chronic kidney disease rats. J Clin Invest 2012;122:2543-2553.

84 Dominquez JR, Shlipak MG, Whooley MA, Ix $\mathrm{JH}$ : Fractional excretion of phosphorus modifies the association between fibroblast growth factor-23 and outcomes. J Am Soc Nephrol 2013;24:647-654

85 Hu MC, Shi M, Zhang J, Quinones H, Kuro-o M, Moe OW: Klotho deficiency is an early biomarker of renal ischemia-reperfusion injury and its replacement is protective. Kidney Int 2010;78:1240-1251.
86 Sugiura H, Yoshida T, Mitobe M, Yoshida S, Shiohira S, Nitta K, et al: Klotho reduces apoptosis in experimental ischaemic acute kidney injury via HSP-70. Nephrol Dial Transplant 2010;25:60-68.

87 Morishita K, Shirai A, Kubota M, Katakura Y, Nabeshima Y, Takeshige K, et al: The progression of aging in klotho mutant mice can be modified by dietary phosphorus and zinc. J Nutr 2001;131:3182-3188.

88 Mitani H, Ishizaka N, Aizawa T, Ohno M, Usui S, Suzuki T, et al: In vivo klotho gene transfer ameliorates angiotensin II-induced renal damage. Hypertension 2002;39:838-843. 